\title{
Divergence in Accuracy of Diabetes Screening Methods in Tuberculosis Patients: A Cross-Sectional Study from Brazil and Peru
}

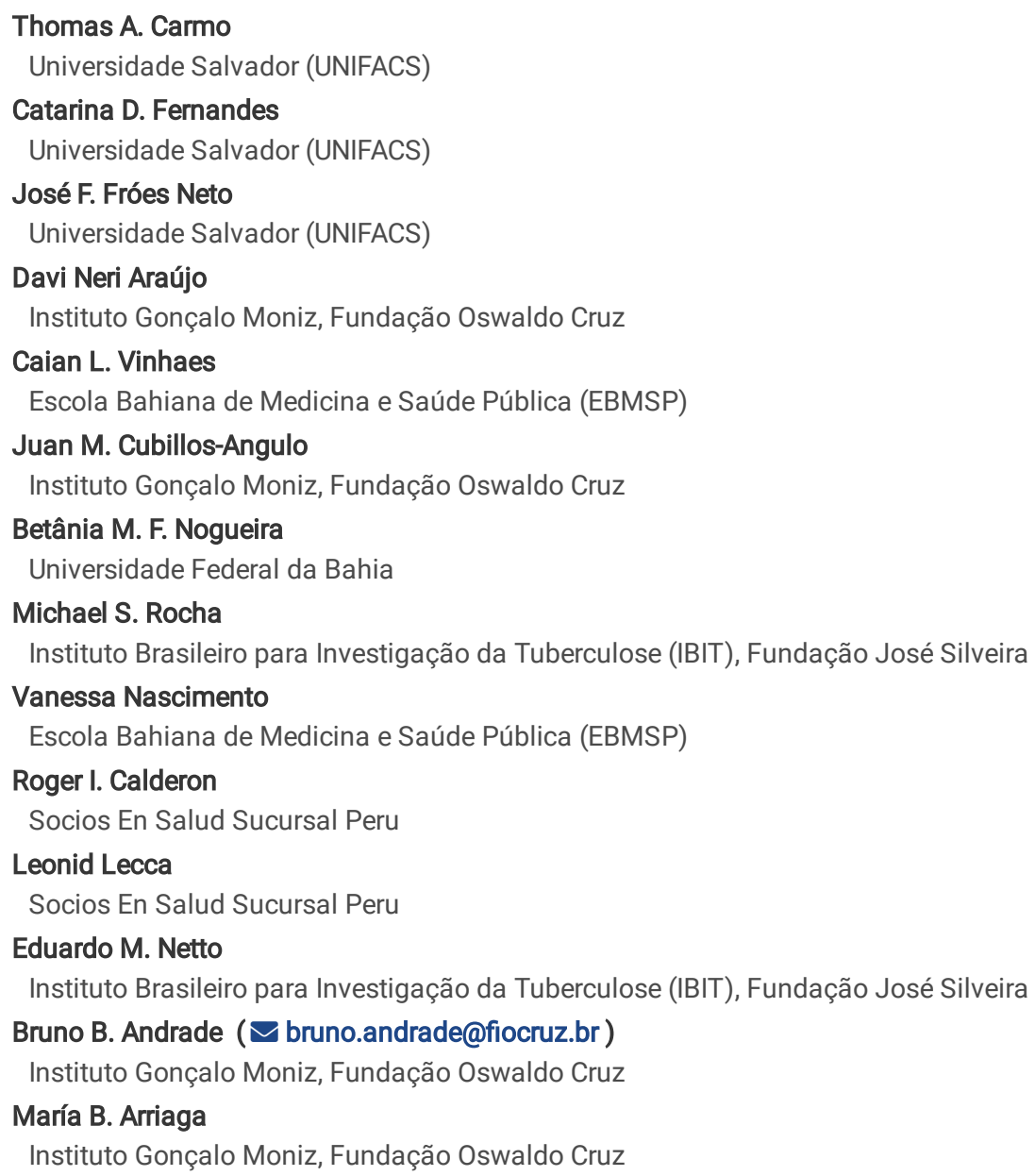

\section{Research Article}

Keywords: fasting plasma glucose, hemoglobin A1c, diabetes mellitus, prediabetes, tuberculosis

Posted Date: May 5th, 2021

DOI: https://doi.org/10.21203/rs.3.rs-477898/v1

License: (c) (i) This work is licensed under a Creative Commons Attribution 4.0 International License. Read Full License 


\section{Abstract}

To evaluate the accuracy of distinct diabetes mellitus (DM) screening methods in persons with active Tuberculosis PWTB.

Levels of fasting plasma glucose (FPG) and glycated hemoglobin (HbA1c) at the time of tuberculosis diagnosis at the study clinics were assessed from two distinct retrospective cohorts of PWTB from Brazil $(n=116)$ and Peru $(n=136)$ to evaluate accuracy for detecting pre-DM and DM cases. Additionally, we investigated the association of clinical and sociodemographic factors with tuberculosis and pre-DM or DM in each country.

When comparing PWTB from Brazil and Peru, Peruvian individuals presented higher FPG levels at baseline (median [IQR] 91 [81-106 vs 95 [88.4102.1]; $p=0.02$ ), while those from Brazil had significant higher levels of HbA1c (median [IQR] 6.3 [5.7-7.15] vs 5.1 [4.9-5.4]; $p<0.01$ ). Additional analysis using the receiver operating characteristic curve revealed that the markers showed distinct accuracy to identify dysglycemia among PWTB in each country.

Our findings indicate that there are significant differences in the total accuracy of the glycemic screening methods evaluated between PWTB from two highly endemic countries from South America, highlighting the need to revisit the diagnostic criteria of DM/PDM in individuals with tuberculosis.

\section{Introduction}

Tuberculosis (TB) is a major public health concern at global level. In 2019, The World Health Organization (WHO) estimated 10 million new cases and 1.4 million deaths caused by TB ${ }^{1}$. Notably, among risk factors associated with TB morbidity and mortality, it is a common knowledge that glycemic disorders such as diabetes mellitus (DM) and prediabetes (PDM), exhibit critical influence over immune pathology and systemic inflammation, thus increasing risk of worse clinical outcomes ${ }^{2-4}$. Moreover, it is known that DM triples active TB risk and exacerbates TB clinical presentation resulting in early mortality rates (death within 100 days of starting anti-TB treatment) and increasing the odds of unfavorable TB treatment outcomes ${ }^{2-6}$. On the converse, TB may lead to infection-related hyperglycemia, often decompensating glycemic control in diabetics ${ }^{4,5}$. Hence, the relationship between dysglycemic states and TB is bidirectional, establishing a mutual harmful association.

TB and DM convergence results in a significant disease worldwide, especially in low and middle-income countries ${ }^{3,7}$. Indeed, despite all TB therapeutic strategies and preventive support improvement, Brazil remains among the 20 countries with the highest disease burden in the world and number one in the Americas, followed by Peru ${ }^{1,8}$. While Brazil is responsible for the largest number of absolute cases for its large population, Peru has the second highest incidence rate in the Americas (123/100.000 versus 45/100.000 in Brazil) ${ }^{8}$. In Brazil, 7.6\% of incident TB cases are associated to DM ${ }^{9}$. As an effort to decrease the impact caused by TB-DM syndemic, the WHO as well as the Peruvian and the Brazilian National TB Program (NTP and PNCT, respectively) recommend screening for DM those presenting with active TB and frequent screening for TB symptoms in persons with DM (PWDM) $1,10,11$.

In the clinical practice, fasting plasma glucose (FPG) and glycated hemoglobin ( $\mathrm{HbA1c}$ ) are the most frequent tests used to diagnose DM, followed by the oral glucose tolerance test (OGTT) ${ }^{5,12}$. OGTT is considered the gold standard for DM diagnosis, but it has some expressive limitations as a mass screening test, due to the uncertainty of the fasting state, the time-consuming nature of the test, poor reproducibility of the results and need of a standard $75 \mathrm{~g}$ glucose load, which is a challenge in primary care settings in resource-limited countries $5,13,14$. Nevertheless, the accuracy of HbA1c and FPG can be limited by issues such as accuracy variation among subjects of different ethnicity ${ }^{15}$. Of note, previous investigations assessing accuracy of these laboratory parameters for screening of DM in PWTB exposed conflicting results in different populations, especially in those from South America ${ }^{13,16}$. This could result from blood tests being affected by ethnicity and genetic variations influencing hemoglobin concentrations in peripheral blood ${ }^{17}$, strengthening the hypothesis that unique features determined by genetic background might have an impact on the choice of the most reliable DM screening method.

In the present study, we investigated the performance of HbA1c and FPG in identifying PDM and DM cases among PWTB from two South American countries with high burden for both TB and DM, Brazil, and Peru. Differences in associations of clinical and sociodemographic characteristics with TB and dysglycemia between the countries were also examined.

\section{Methods}

\section{Ethics statement}

All clinical investigations were conducted according to the principles expressed in the Declaration of Helsinki. In Brazil, the study was approved by the Ethics Committee of the Maternidade Clímério de Oliveira, Federal University of Bahia (protocol number: 037/2011, Ethics Committee approval number: 034/11). Peruvian research was approved by the Institutional Committee of Ethics for Humans (CIEl, approval number: 158-22-16), the Universidad Peruana Cayetano Heredia. Written informed consent was obtained from all participants or their legally responsible guardians.

\section{Study design and population in Brazil}


We conducted a retrospective cross-sectional study of data retrieved from a prospective cohort conducted between May 2010 and June 2011 in the Instituto Brasileiro para Investigação da Tuberculose (IBIT), Fundação José Silveira, Salvador, Brazil, which aimed to examine the association between glucose metabolism disorder and pulmonary TB ${ }^{35}$. For the present study, the inclusion criteria were patients $\geq 18$ years of age, diagnosed with $T B$ according to the Brazilian Manual of Recommendations for TB Control ${ }^{10}$ and who were not undertaking anti-TB drugs for more than 5 days, whereas incomplete medical report was considered as the exclusion criteria. Sociodemographic and clinical characteristics were collected by trained physicians during each patient visit and recorded in standardized electronic forms, which are part of the Brazilian National TB control program. Moreover, as part of the laboratory investigation, three sputum smears stained by Ziehl-Neelsen and examined by microscopy at the IBIT's microbiology referral laboratory, processed by the modified Petroff's method and cultured on Lowenstein-Jensen medium. Diagnosis of DM or PDM was performed at the time of TB diagnosis (baseline visit) in agreement with American Diabetes Association (ADA) guidelines ${ }^{32}$, and was based on fasting plasma glucose (FPG), glycated hemoglobin ( $\mathrm{HbA1c}$ ) and oral glucose tolerance test (OGTT) as previously described ${ }^{35}$. Further details about the study site and data management are described in previously published studies ${ }^{35,36}$.

\section{Study design and population in Peru}

We retrospectively analyzed data of 136 individuals diagnosed with pulmonary TB, from a larger prospective cohort study conducted over February and November 2017 with patients from North Lima, Peru ${ }^{2}$. TB diagnosis was performed by the National TB Program (all patients had microbiologically confirmed TB) and inclusion criteria comprised patients with age $\geq 18$ years and who were not receiving anti-TB treatment or had started in no more than 5 days. Information on sociodemographic and clinical evaluation was retrieved from the medical records. All enrolled participants provided sputum samples for acid-fast bacilli (AFB) smear, which were stained by Ziehl-Neelsen and examined by microscopy. Then sputum specimens were cultured by Lowenstein-Jensen medium and BD MGIT 960 System (liquid culture). Smear and cultures were graded according to AFB and colonies numbers following standard guidelines ${ }^{37}$. Evaluation of glycemic markers, FPG, HbA1c and OGTT, was performed to establish DM or PDM diagnosis according to ADA criteria ${ }^{32}$. Such procedures were performed at the baseline clinical visit when TB was diagnosed. Measurement of $\mathrm{HbA1c}$ in blood was conducted using TRI-stat ${ }^{\text {TM }}$ platform (Trinity Bio- tech, Ireland). FPG and OGTT were performed following standard methods. Supplementary information about procedures and patient management, are well described in previous publications ${ }^{2,6}$.

\section{Epidemiological characteristics of TB and DM in Brazil and Peru.}

Overall distribution of TB and DM cases in both countries was described accordingly with the data gathered from the international reports published by the $\mathrm{WHO}^{8}$ and International Diabetes Federation ${ }^{18}$. Such distribution is shown in Figure 1.

\section{Data analysis}

Descriptive analysis was performed with categorical variables presented as frequency and percentages and compared using the Fisher's exact test (between 2 groups) or Pearson's chi-square test (more than 2 groups), when appropriate. Quantitative variables were expressed as median with interquartile range (IQR) and compared using the Mann-Whitney $U$ test, for two groups, or the Kruskal Wallis test with Dunn's multiple comparisons posttest for more than two groups. Analyses of stratified or matched categorical data were performed with Cochran-Mantel-Haenszel test. The Kappa (K) statistic test was calculated to assess agreement between FPG or HbA1c as diagnostic test for DM/PDM in both countries. Kappa statistic results were interpreted using the Landis and Koch criteria ${ }^{38}$. All tests were pre-specified, two-tailed and differences were considered statistically significant with $\mathrm{p} \leq$ 0.05. Data analysis was performed using SPSS 24.0 (IBM statistics), Graphpad Prism 7.0 (GraphPad Software, San Diego, CA) and JMP 13.0 (SAS, Cary, NC, USA).

\section{Results}

\section{TB and DM burden in Brazil and Peru}

The overall distribution of TB and DM cases using the most updated report containing estimated data from both countries, performed in 2019, is shown in Figure $\mathbf{1}^{8,18}$. Brazil led the burden of TB in South and Central America, with a total of 96,000 TB cases reported and a rate of 46 cases per 100,000 inhabitants, while Peru had a total of 39,000 TB cases estimated and a rate of 119/100,000. Regarding DM distribution, more than 16.8 million cases were reported among Brazilians, with a rate of 80 cases per 100,000 estimated in $2019{ }^{1}$ and among Peruvian approximately 22 cases per $100,000{ }^{19}$ Furthermore, the cohort explored in the present study was located in state of Bahia, represented in the map with an incidence of TB-DM of 9 cases per 100 inhabitants. Similarly, the Province of Lima, from where our Peruvian cohort was followed, had an incidence of 10 cases per 100 inhabitants of TBDM comorbidity in 2019. Therefore, our cohorts are originated from relevant endemic areas with relatively high burden of both TB and DM.

\section{Characteristics of the study populations}

Brazilian participants were significantly older than the Peruvians, (median age [IQR]: 45 [31-55] vs. 29 [IQR: 23-45], respectively; p < 0.01) (Table 1). Distribution of sex was similar between the cohorts (Table 1). With respect to clinical presentation, we found that Brazilian participants presented more frequently with cough $(p<0.01)$, fever $(<0.01)$ and weight loss $(p=0.03)$, whereas individuals from Peru more often had hemoptysis $(p<0.01)$ and lack of appetite ( $p=0.02$ ) (Table 1 and Supplementary Figure 1). Moreover, Peruvians exhibited higher FPG levels (median [IQR] 95 [88.4-102.1] vs 91 [81-106]; $p=0.02$ ), while Brazilian displayed more elevated HbA1c values $(p<0.01)$. There was no difference in median OGTT level among the two populations 
(Table 1). Smoking history was more commonly reported in patients from Brazil (39.7\% vs 21.5\%, $p<0.01)$, while current illicit drug use and alcohol consumption were more frequent in Peruvians $(p<0.01)$ (Table 1). Metformin use was more frequently documented in Peruvian participants than that in those from Brazil (11.4\% vs 1.3\%, p< 0.01). Finally, Peruvians more often were BCG vaccinated than Brazilians (93.3\% vs 75.4\%, $<<0.01)$. Additional comparisons are depicted in Table 1.

\section{Distribution of TB cases according to glycemic status in Brazil and Peru}

We next stratified the study participants in both countries based on the final diagnosis of the glycemic status (e.g., normoglycemic, PDM and DM). In Brazil, $42.2 \%$ of the PWTB had also DM and $41.4 \%$ had PDM (Table 2 ). In contrast, in Peru, $13.9 \%$ of the PWTB had comorbid DM, followed by $31 \%$ who had PDM (Table 2). DM was associated with older age in both countries and the group with highest median age were Brazilians individuals with DM (50.1 [IQR: 45-59], $\mathrm{p}<0.01$ ) (Table 2). Among the TB clinical symptoms, hemoptysis was more prevalent in Peruvian patients with DM (47.4\%; $p<0.01$ ) (Table 2). When all the TB patients were considered, we found HbA1c $(p<0.01)$ and OGTT $(p<0.01)$ values higher in Brazil, while FPG levels $(p<0.01)$ higher in Peru (Table 2). Sputum culture grade values tended to be higher following hyperglycemia degree, with Brazilian patients exhibiting a greater frequency of higher culture grades $(p<0.01)$.

\section{Heterogeneity in values from the glycemic screening laboratory tests between persons with TB from Brazil and Peru}

FPG and $\mathrm{HbA} 1 \mathrm{c}$ value distribution in patients from both countries are shown in Figure 2. To better understand the value distribution obtained in the distinct screening tests in the study populations, we initially segregated participants in two groups, including: (i) those with normoglycemia and (ii) individuals with dysglycemia (PDM or DM). Dysglycemia was more prevalent among Brazilian participants (83.6\%) (Figure 2A). However, FPG levels in this group showed that most individuals with dysglycemia presented values under the reference baseline, whereas, in Peru, $70.5 \%$ of patients with DM/PDM exhibited values above the limit for dysglycemia with this marker (Figure 2A). Comparison of FPG median values also displayed differences between countries $(\mathrm{p}<0.05)$, with higher levels found in the Peruvian cohort (Figure $2 \mathrm{C}$ ). On the other hand, HbA1c levels had an inverse distribution in both populations (Figure 2B), in which Brazilians presented the vast majority of values above the reference for DM/PDM diagnosis. In addition, the median values of $\mathrm{HbA1c}$ showed to be significantly increased among Brazilians in comparison with Peru ( $<<0.001)($ Figure 2D). These results suggest that the glycemic screening methods showed a distinct behavior according to the country.

\section{Glycemic screening methods among TB cases}

Next, we aimed to evaluate FPG and HbA1c level distribution according to the following groups: TB, TB-DM and TB-PDM. (Figure 3). Using a demographic density analysis with histograms, we found a similar distribution of FPG values and HbA1c percentage on both countries, where TB normoglycemic participants demonstrated a peak curve in lower FPG levels, followed by TBPDM (Figure 3A). Of note, our findings revealed that the TBDM group displayed wider distribution in both country curves (Figure 3A).

To better understand the differences in the glycemic markers according to TB-DM comorbidity between the two countries, we compared the levels of FPG and HbA1c in TB, TB-PDM and TB-DM groups in Brazil and Peru (Figure 3B). In all clinical groups, levels of FPG were higher among the Peruvians, whereas Brazilians displayed higher HbA1c values, except for the TBDM group (Figure 3B).

\section{Distinct accuracy of glycemic screening methods in dysglycemia diagnosis among TB South American individuals.}

In order to extend our investigations concerning the discriminative performance of glycemic markers to diagnose dysglycemia in TB patients, a receiver operating characteristic (ROC) curve analysis using values of the glycemic markers was employed in each country (Figure 4). HbA1c exhibited a good performance to identify dysglycemia the Brazilian cohort, with an area under curve (AUC) of 0.98 (Cl: 0.93-1.00) (Figure 4A), whereas FPG demonstrated superior performance among Peruvians (AUC: 0.90; $\mathrm{Cl}, 0.84-0.95$ ) (Figure 4B). We next compared the different cohorts with regard to the performance of the FPG or HbA1c tests in distinguishing dysglycemia and found substantial differences between the AUC ( $p=0.0089$ and $p<0.0001$ correspondingly) (Figure 4C). This finding reinforces the idea that there are important discrepancies in the overall accuracy of the FPG and of HbA1c tests to identify individuals with prediabetes or diabetes between Brazilians and Peruvians.

Finally, additional comparisons were made to narrow down the concordance between HbA1c and FGP to detect diabetes or prediabetes in the study populations. We noted that the FPG test had a good degree of agreement in the Peruvian cohort for identification of dysglycemia cases ( $k=0.77$ ) or PDM ( $k=0.6)$, and very good degree for identification of DM individuals $(k=0.96)$. Interestingly, for Brazilian cohort the degree of concordance for identification of dysglycemia or PDM was poor ( $k=0.20$ and $k=0.08$, correspondingly) and for DM it was moderate ( $k=0.11$ ) (Figure 4D). In contrast, the $\mathrm{HbA} 1 \mathrm{c}$ test exhibited a very good agreement in the Brazilian cohort to detect dysglycemia $(\mathrm{k}=0.83), \mathrm{DM}(\mathrm{k}=0.98)$ or PDM ( $\mathrm{k}=0.84)$. Meanwhile, in the Peruvian cohort, the agreement for dysglycemia was moderate $(k=0.44)$, for DM it was very good ( $k=0.97)$ and for PDM it was just fair ( $k=0.35$ ).

\section{Discussion}

The findings presented here depict a detailed investigation of the performance of two tests widely used for assessment of dysglycemia among PWTB from Brazil and Peru. The studied countries represent an expressive portion of TB cases and around of 50\% of Latin American cases in the world, with also elevated prevalence of DM and PDM ${ }^{1,8,18}$. As discussed, PWTB with concurrent uncontrolled glycemic status have an increased risk of increased morbidity and poor treatment outcomes ${ }^{20,21}$. Therefore, there is an urgent need for systematic screening of dysglycemia in PWTB, in order to reach 
those at highest risk of disease complications. Understanding the peculiarities of diagnosing dysglycemia in TB cases in different populations is key to develop focused control strategies adapted to local epidemiological trends.

Our analyses revealed that the accuracy of HbA1c and FPG to diagnose dysglycemia in PWTB differs between Brazil and Peru, with a better performance of $\mathrm{HbA} 1 \mathrm{c}$ in Brazil and FPG in Peru. Findings from studies in other countries reinforce the idea that there is heterogeneity in performance of DM screening tests in PWTB. A study from India has demonstrated that HbA1c performed better than FPG with an AUC of 0.754 (0.682-0.828) for newly diagnosed DM among subjects with $\mathrm{TB}^{13}$. Furthermore, a Pakistan study showed that the proportion of participants falsely classified as positive was higher for FPG, although the performance of HbA1c and FPG had no differences in terms of diagnosing new DM cases ${ }^{17}$. In a recent study, FPG levels were able to detect more cases of PDM in PWTB from Peru than HbA1c ${ }^{2}$. In a Chinese study, FPG performed better than HbA1c in identifying newly diagnosed DM and PDM ${ }^{22}$. Such peculiarities in test performance to diagnose dysglycemia reported in different countries may be determined by genetics, environmental factors or a combination of both and should be explored in future mechanistic studies.

Previous studies have shown that HbA1c values vary according to ethnicity, even in individuals without dysglycemia ${ }^{23,24}$. Moreover, abnormalities of erythrocyte indices are considerable confounders in the analysis of HbA1c ${ }^{25}$. Possible explanations for this could be hemoglobin-related factors such as red cell turnover, variations in hemoglobin glycation, differences in the passage of glucose mediated by GLUT1 transporter into the erythrocyte, higher prevalence of hemolytic conditions such as glucose-6-phosphate dehydrogenase deficiency or sickle cell trait, among others ${ }^{24,26}$. Genetic factors can also modulate $\mathrm{HbA} 1 \mathrm{c}$ levels with heritability of $47 \%$ to $59 \%{ }^{27}$. Interestingly, a genetic risk score, based on the 14 single nucleotide polymorphisms (SNPs) found that some people had a higher genetic risk of higher levels of fasting plasma glucose ${ }^{28}$. Regarding DM in PWTB, a multicentric prospective study compared the accuracy of random plasma glucose, point-of-care HbA1c, FPG, urine dipstick, risk scores and anthropometric measurements, using $\mathrm{HbA} 1 \mathrm{C}$ as a golden standard. They also found heterogeneous performance of laboratory markers to diagnose DM across countries ${ }^{12}$.

More than identifying the reasons for $\mathrm{HbA1c}$ variation among populations, it is essential to know what the clinical importance of these findings is. It is still under discussion how this variation in test performance can affect DM outcomes, but some studies have found no difference in long term risk for cardiovascular disease, final-stage renal disease and retinopathy $24,29,30$. To our knowledge, no studies to date have evaluated the influence of $\mathrm{HbA} 1 \mathrm{C}$ accuracy variation in TB outcomes. A previous study reported higher HbA1c values being predictive of unfavorable outcomes in PWTB ${ }^{31}$, but there was no comparison between populations with distinct genetic backgrounds.

The ADA guidelines for DM recommends that any of three diagnostic test mentioned in this study can be used to diagnose $D M{ }^{32}$. The Brazilian guidelines use the same criteria as ADA and the Peruvian guidelines have not included $\mathrm{HbA} 1 \mathrm{c}$ as a diagnostic tool because of its low availability in the public health system and lack of standardization in the country ${ }^{33,34}$. Our findings suggest that the use of HbA1c should be used with caution in the diagnosis, as the cutoff is still inconsistent and may vary in dissimilar populations. It is possible that different thresholds need to be used in different populations.

More research needs to be done in evaluating the impact of variability in DM screening test accuracy in TB treatment outcome. Moreover, additional studies are required to define the most reliable screening methods for each population. As an example, Grint D, et al tested a combination of two tests that increased DM diagnosis accuracy in PWTB from Peru and Indonesia, but not in other countries ${ }^{12}$. Meanwhile, standard diagnostic thresholds should be used with caution, particularly in the population with greater variability of tests results. Clinicians should also be attentive for factors that are predictors of high glycemia, such as older age, hypertension, and increased body mass index ${ }^{23}$ and repeat or associate a different method when there is high pre-test probability of dysglycemia.

Common limitations of retrospective investigations should be acknowledged in our study. Our investigations could not determine the major factors responsible for the heterogeneity observed between countries, concerning ethnicity, severe anemia, and genetic variations in hemoglobin. Additionally, the dissonances found regarding the distinct glycemic status on each group analyzed may have affected the accuracy of our findings in terms of confidence intervals. Finally, there was not a gold standard such as OGTT test used for the evaluation of accuracy. Nevertheless, given our diversified and well characterized cohorts, our conclusions do extend the current knowledge in the field by demonstrating a significant variability in accuracy of FPG and HbA1c to diagnose dysglycemia in TB patients across countries.

Our findings provide relevant insights over the significance of intrinsic elements of each population when choosing the most reliable laboratory method for screening and diagnosis of glycemic disorders in PWTB. The analysis presented here demonstrate different discriminative results for dysglycemia diagnosis among individuals with TB, remarkable by a superior performance of HbA1c in Brazil, whilst FPG presented a better accuracy within Peruvians.

\section{Declarations}

Acknowledgments: The authors would like to thank the study participants and Mrs. Elze Leite for logistics and administrative support. The Brazilian part of this study was supported by the Intramural Research Program of the Fundação Oswaldo Cruz (B.B.A.), Intramural Research Program of the Fundação José Silveira (E.M.N., M.S.R., V.N., B.M.F.N.) and the National Institutes of Allergy and Infectious Diseases [U01-Al069923 and U01-Al115940 to B.B.A.]. B.B.A. is a senior investigator of the Conselho Nacional de Desenvolvimento Científico e Tecnológico (CNPq), Brazil. M.B.A., T.A.C, C.D.F. and 
J.F.F.N. received a fellowship from the Fundação de Amparo à Pesquisa da Bahia (FAPESB) whereas D.N.A received a fellowship from CNPq, Brazil. The Peruvian part of this study was supported by the Consejo Nacional de Ciencia, Tecnología e Innovación Tecnológica (CONCYTEC-Perú) / Fondo Nacional de Desarrollo Científico, Tecnológico y de Innovación Tecnológica (FONDECYT) (grant number 173, 2015). The funder of the study had no role in the study design, data collection, or data analysis.

Author contributions: Conceptualization, M.B.A and B.B.A.; Data curation, R.I.C., M.S.R and B.B.A.; Investigation, T.A.C., M.B.A and B.B.A.; Formal analysis, J.F.F., C.L.V. and B.B.A.; Funding acquisition, E.M.N., L.L., B.B.A.; Methodology, C.D.F, D.N.A. and B.B.A.; Project administration, E.M.N., R.I.C. and B.B.A.; Resources, B.B.A. Software, B.B.A.; Supervision, B.M.F.N, J.M.C-A. and B.B.A.; Writing-original draft, T.A.C. and B.B.A.; Writing-review and editing, all authors. All authors have read and agreed to the submitted version of the manuscript.

Data availability statement: The datasets generated during and/or analysed during the current study are available from the corresponding author on reasonable request.

Competing interests: The authors declare that they have no conflicts of interest.

\section{References}

1. Global tuberculosis report 2020. Geneva: World Health Organization; 2020. Licence: CC BY-NC-SA 3.0 IGO.

2. Calderon, R. I. et al. High prevalence and heterogeneity of Dysglycemia in patients with tuberculosis from Peru: A prospective cohort study. $B M C$ Infect. Dis. 19, 1-11 (2019).

3. Noubiap, J. J. et al. Global prevalence of diabetes in active tuberculosis: a systematic review and meta-analysis of data from $2 \cdot 3$ million patients with tuberculosis. Lancet Glob. Heal. 7, e448-e460 (2019).

4. Dooley, K. E. \& Chaisson, R. E. Tb and Dm, Converge of Two Epidemics. Lancet Infect Dis. 9, 737-746 (2010).

5. Huangfu, P. et al. Point of care HbA1c level for diabetes mellitus management and its accuracy among tuberculosis patients: a study in four countries. Int J Tuberc Lung Dis. 23, 283-292 (2019).

6. Barreda, N. N. et al. Severe pulmonary radiological manifestations are associated with a distinct biochemical profile in blood of tuberculosis patients with dysglycemia. BMC Infect. Dis. 20, 1-14 (2020).

7. Workneh, M. H., Bjune, G. A. \& Yimer, S. A. Prevalence and associated factors of tuberculosis and diabetes mellitus comorbidity: A systematic review. PLoS One. 12, 1-25 (2017).

8. Global tuberculosis report 2019. Geneva: World Health Organization; 2019. Licence: CC BY-NC-SA 3.0 IGO.

9. Panorama da tuberculose no Brasil: diagnóstico situacional a partir de indicadores epidemiológicos e operacionais [recurso eletrônico] / Ministério da Saúde, Secretaria de Vigilância em Saúde, Departamento de Vigilância das Doenças Transmissíveis. - Brasí.

10. Brasil Manual de para o Controle da Tuberculose. Ministério da Saúde(2019).

11. Ministerio de Salud. Norma Técnica de Salud para la Atención Integral de las personas afectadas por Tuberculosis. 128 (2013).

12. Grint, D. et al. Accuracy of diabetes screening methods used for people with tuberculosis, Indonesia, Peru, Romania, South Africa. Bull. World Health Organ. 96, 738-749 (2018).

13. Kumpatla, S., Aravindalochanan, V., Rajan, R., Viswanathan, V. \& Kapur, A. Evaluation of performance of A1C and FPG tests for screening newly diagnosed diabetes defined by an OGTT among tuberculosis patients-A study from India. Diabetes Res. Clin. Pract. 102, 60-64 (2013).

14. Jesudason, D. R., Dunstan, K., Leong, D. \& Wittert, G. A. Macrovascular Risk and Diagnostic Criteria for Type 2 Diabetes: Implications for the use of FPG and HbA1c for cost-effective screening. Diabetes Care. 26, 485-490 (2003).

15. Yu, E. Y. T., Wong, C. K. H., Ho, S. Y., Wong, S. Y. S. \& Lam, C. L. K. Can HbA1c replace OGTT for the diagnosis of diabetes mellitus among Chinese patients with impaired fasting glucose? Fam. Pract. cmv077 https://doi.org/10.1093/fampra/cmv077 (2015).

16. Boillat-Blanco, N. et al. Transient Hyperglycemia in Patients With Tuberculosis in Tanzania: Implications for Diabetes Screening Algorithms. J. Infect. Dis. 213, 1163-1172 (2016).

17. Aftab, H. et al. Comparative study of $\mathrm{HbA} 1 \mathrm{c}$ and fasting plasma glucose vs the oral glucose tolerance test for diagnosis of diabetes in people with tuberculosis. Diabet. Med. 34, 800-803 (2017).

18. International Diabetes Federation. IDF Diabetes Atlas, 9th edn. Brussels, Belgium: 2019.

19. Ministerio de Salud DPCTB: Portal de Información: Perfil de la Tuberculosis - PERU [Internet]. Dirección de Prevención y Control de Tuberculosis.

20. Chen, L., Magliano, D. J. \& Zimmet, P. Z. The worldwide epidemiology of type 2 diabetes mellitus-present and future perspectives. Nat. Rev. Endocrinol. 8, 228-236 (2011).

21. Jeon, C. Y. \& Murray, M. B. Diabetes mellitus increases the risk of active tuberculosis: A systematic review of 13 observational studies. PLoS Med. 5, 1091-1101 (2008).

22. Zhou, X. et al. Performance of an A1C and fasting capillary blood glucose test for screening newly diagnosed diabetes and pre-diabetes defined by an oral glucose tolerance test in Qingdao, China. Diabetes Care. 33, 545-550 (2010). 
23. Herman, W. H. et al. Differences in A1C by Race and Ethnicity Among Patients With Impaired Glucose Tolerance in the Diabetes Prevention Program. Diabetes Care. 30, 2453-2457 (2007).

24. Cavagnolli, G., Pimentel, A. L., Freitas, P. A. C., Gross, J. L. \& Camargo, J. L. Effect of ethnicity on HbA1c levels in individuals without diabetes: Systematic review and meta-analysis. PLoS One. 12, e0171315 (2017).

25. English, E. et al. The effect of anaemia and abnormalities of erythrocyte indices on HbA1c analysis: a systematic review. Diabetologia. 58, 14091421 (2015).

26. Selvin, E. Are There Clinical Implications of Racial Differences in HbA 1c ? A Difference, to Be a Difference, Must Make a Difference. Diabetes Care. 39, 1462-1467 (2016).

27. Soranzo, N. Genetic determinants of variability in glycated hemoglobin $(\mathrm{HbA}(1 \mathrm{c}))$ in humans: review of recent progress and prospects for use in diabetes care. Curr. Diab. Rep. 11, 562-569 (2011).

28. Wang, T. et al. Genetic variation of fasting glucose and changes in glycemia in response to 2-year weight-loss diet intervention: the POUNDS LOST trial. Int. J. Obes. (Lond). 40, 1164-1169 (2016).

29. Bower, J. K., Brancati, F. L. \& Selvin, E. No Ethnic Differences in the Association of Glycated Hemoglobin With Retinopathy: The National Health and Nutrition Examination Survey 2005-2008. Diabetes Care. 36, 569-573 (2013).

30. Effects of Intensive Glucose Lowering in. Type 2 Diabetes. N. Engl. J. Med. 358, 2545-2559 (2008).

31. Mburu, J. W., Kingwara, L., Ester, M. \& Andrew, N. Use of classification and regression tree (CART), to identify hemoglobin A1C (HbA1C) cut-off thresholds predictive of poor tuberculosis treatment outcomes and associated risk factors. J. Clin. Tuberc. Other Mycobact. Dis. 11, 10-16 (2018).

32. Care, D. \& Suppl, S. S. 2. Classification and diagnosis of diabetes: Standards of medical care in diabetesd2019. Diabetes Care. 42, S13-S28 (2019).

33. Diretrizes da Sociedade Brasileira de Diabetes 2019-2020. Sociedade Brasileira de Diabetes.

34. García, P., Pessah, S. \& Pun, M. N. M. Guía de práctica clínica para el diagnóstico, tratamiento y control de la diabetes mellitus tipo 2 en el primer nivel de atención. 1st ed. Lima: Dirección de Prevención de Enfermedades No Transmisibles y Oncológicas; 2016.

35. Almeida-Junior, J. L. et al. Glucose metabolism disorder is associated with pulmonary tuberculosis in individuals with respiratory symptoms from Brazil. PLoS One. 11, 1-14 (2016).

36. Gil-Santana, L. et al. Diabetes Is Associated with Worse Clinical Presentation in Tuberculosis Patients from Brazil: A Retrospective Cohort Study. PLoS One. 11, e0146876 (2016).

37. Organización Panamericana de la salud. Manual Para el Diagnóstico Bacteriológico de la TBC. Organizacion Panamericana de la Salud. 1, 66 (2008).

38. Brennan-Jones, C. G., Eikelboom, R. H., Bennett, R. J., Tao, K. F. M. \& Swanepoel, D. W. Asynchronous interpretation of manual and automated audiometry: Agreement and reliability. J. Telemed. Telecare. 24, 37-43 (2018).

\section{Tables}




\begin{tabular}{|c|c|c|c|c|}
\hline \multirow[t]{2}{*}{ Characteristics } & \multirow[t]{2}{*}{$\mathrm{n} / \mathrm{N}$} & \multirow{2}{*}{$\begin{array}{l}\text { Brazil } \\
n=116\end{array}$} & \multirow{2}{*}{$\begin{array}{l}\text { Peru } \\
n=136\end{array}$} & \multirow[t]{2}{*}{ p-value } \\
\hline & & & & \\
\hline Sex & $116 / 136$ & & & 0.37 \\
\hline Male & & $64(55.2)$ & $83(61)$ & \\
\hline Female & & $52(44.8)$ & $53(39)$ & \\
\hline Age (years) & $116 / 136$ & $45(31-55)$ & $29(23-45)$ & $<0.01$ \\
\hline BMI $\left(\mathrm{Kg} / \mathrm{m}^{2}\right)$ & $115 / 132$ & $22.94[20-26.81]$ & 22.67 [20.57-25.31] & 0.46 \\
\hline Cough & $116 / 136$ & 115 (99.1) & $123(90.4)$ & $<0.01$ \\
\hline Fever & $116 / 136$ & $76(65.5)$ & $63(46.3)$ & $<0.01$ \\
\hline Malaise & $116 / 136$ & $83(71.6)$ & 105 (77.2) & 0.31 \\
\hline Loss of weight & $116 / 136$ & $98(84.5)$ & $99(72.8)$ & 0.03 \\
\hline Night sweats & $116 / 136$ & $79(68.1)$ & $78(57.4)$ & 0.09 \\
\hline Hemoptysis & $116 / 136$ & $24(20.7)$ & $57(41.9)$ & $<0.01$ \\
\hline Lack of Appetite & $116 / 136$ & $87(75)$ & $82(60.3)$ & 0.02 \\
\hline Dyspnea & $116 / 136$ & $70(60.3)$ & $88(64.7)$ & 0.52 \\
\hline Comorbidities & $116 / 136$ & $17(14.7)$ & $16(11.8)$ & 0.58 \\
\hline Smoking History & $116 / 135$ & $46(39.7)$ & $29(21.5)$ & $<0.01$ \\
\hline Illicit drug use & $116 / 135$ & $4(3.4)$ & $21(15.6)$ & $<0.01$ \\
\hline Alcohol consumption & $116 / 135$ & $11(9.5)$ & $70(51.9)$ & $<0.01$ \\
\hline Glycemic Status & $116 / 136$ & & & $<0.01$ \\
\hline DM & & $49(42.2)$ & $19(14)$ & \\
\hline PDM & & $48(41.4)$ & $42(30.9)$ & \\
\hline Normoglycemic & & 19 (16.4) & $75(55.1)$ & \\
\hline Metformin use & $21 / 132$ & $10(1.3)$ & $7(11.4)$ & $<0.01$ \\
\hline FPG (mg /dL) & $116 / 136$ & 91 [81-106] & 95 [88.4-102.1] & 0.02 \\
\hline HbA1c (\%) & $116 / 134$ & $6.3[5.7-7.15]$ & $5.1[4.9-5.4]$ & $<0.01$ \\
\hline OGTT (mg/dL) & $84 / 112$ & 118 [94-154.5] & 112.8 [91.45-127.85] & 0.06 \\
\hline Prior TB & $116 / 136$ & $23(19.8)$ & $23(16.9)$ & 0.62 \\
\hline BCG vaccination & $114 / 135$ & $86(75.4)$ & $126(93.3)$ & $<0.01$ \\
\hline TB contact & $116 / 136$ & $31(26.7)$ & $52(38.2)$ & 0.06 \\
\hline AFB smear & $116 / 130$ & & & 0.99 \\
\hline Negative & & $50(43.1)$ & $60(46.2)$ & \\
\hline Scanty & & $0(0)$ & $0(0)$ & \\
\hline $1+$ & & $27(23.3)$ & $27(20.8)$ & \\
\hline $2+$ & & $18(15.5)$ & 15 (11.5) & \\
\hline $3+$ & & $21(18.1)$ & $28(21.5)$ & \\
\hline L-J culture & $108 / 131$ & & & 0.27 \\
\hline Negative & & $4(3.7)$ & $38(29)$ & \\
\hline Scanty & & $2(1.9)$ & $14(10.7)$ & \\
\hline+1 & & $48(44.4)$ & $63(48.1)$ & \\
\hline+2 & & $33(30.6)$ & $9(6.9)$ & \\
\hline
\end{tabular}


Data are represented as median with interquartile range [25th - 75th percentile] or frequency (percentage). Groups were compared using MannWhitney $U$ test for quantitative variables and the Pearson's qui-square test or Fisher's exact test for categorical variables. $P<0.05$ was considered statistically significant. Comorbidities: Renal disease and/or Asthma and/or Hypertension; Smoking history: Past or current cigarette smoker; Illicit Drugs Use: Past or current illicit drug use (marijuana, cocaine, heroin or crack); Chronic Alcoholism: Past or current any consumption of alcohol; Metformin use: Metformin use in patients with dysglycemia; Prior TB: previous diagnosis of active tuberculosis; DM: Diabetes; PDM: Prediabetes; FPG Fasting Plasma Glucose; HbA1c Glycated Hemoglobin; OGTT Oral Glucose Tolerance Test; BMI: Body Mass Index; BCG: Bacillus CalmetteGuérin; AFB Acid-Fast Bacilli; L-J Löwenstein-Jensen. 


\begin{tabular}{|c|c|c|c|c|c|c|c|c|c|c|}
\hline \multirow[t]{3}{*}{ Characteristics } & \multicolumn{4}{|l|}{ TOTAL } & \multicolumn{3}{|l|}{ BRAZIL } & \multicolumn{2}{|l|}{ PERU } & \multirow{3}{*}{$\begin{array}{l}\mathrm{p}- \\
\text { value }\end{array}$} \\
\hline & DM & PDM & Normoglycemic & DM & $\begin{array}{l}\text { Pre- } \\
\text { DM }\end{array}$ & Normoglycemic & DM & $\begin{array}{l}\text { Pre- } \\
\text { DM }\end{array}$ & Normoglycemic & \\
\hline & $n=68$ & $n=90$ & $n=94$ & $n=49$ & $n=48$ & $n=19$ & $n=19$ & $n=42$ & $n=75$ & \\
\hline Sex & & & & & & & & & & 0.79 \\
\hline Male & $\begin{array}{l}42 \\
(61.8)\end{array}$ & $51(56.7)$ & $54(57.4)$ & $\begin{array}{l}33 \\
(67.3)\end{array}$ & $24(50)$ & $7(36.8)$ & $\begin{array}{l}9 \\
(47.4)\end{array}$ & $\begin{array}{l}27 \\
(64.3)\end{array}$ & $47(62.7)$ & \\
\hline Female & $\begin{array}{l}26 \\
(38.2)\end{array}$ & $39(43.3)$ & $40(42.6)$ & $\begin{array}{l}16 \\
(32.7)\end{array}$ & $24(50)$ & $12(63.2)$ & $\begin{array}{l}10 \\
(52.6)\end{array}$ & $\begin{array}{l}15 \\
(35.7)\end{array}$ & $28(37.3)$ & \\
\hline Age (years) & $\begin{array}{l}50.1 \\
{[42.8-} \\
58.6]\end{array}$ & $\begin{array}{l}39.5[26.0 \\
-52.0]\end{array}$ & 27.7 [22.2-33.0] & $\begin{array}{l}50.81 \\
{[45.0-} \\
59.0]\end{array}$ & $\begin{array}{l}39.3 \\
{[26.0-} \\
52.3]\end{array}$ & $33.0[27.7-44.7]$ & $\begin{array}{l}46.4 \\
{[36.6-} \\
58.3]\end{array}$ & $\begin{array}{l}39.8 \\
{[26.7-} \\
51.4]\end{array}$ & 25.8 [21.0-31.0] & $<0.01$ \\
\hline $\mathrm{BMI}\left(\mathrm{Kg} / \mathrm{m}^{2}\right)$ & $\begin{array}{l}22.68 \\
{[20.02-} \\
26.36]\end{array}$ & $\begin{array}{l}23.0[20.6 \\
-26.0]\end{array}$ & $22.4[20.2-26.1]$ & $\begin{array}{l}22.94 \\
{[20.0-} \\
26.4]\end{array}$ & $\begin{array}{l}22.5 \\
{[20.2-} \\
27.1]\end{array}$ & $\begin{array}{l}23.32 \text { [19.6- } \\
28.4]\end{array}$ & $\begin{array}{l}22.3 \\
{[21.4-} \\
26.4]\end{array}$ & $\begin{array}{l}23.2 \\
{[21.2-} \\
25.1]\end{array}$ & 22.3 [20.3-25.4] & 0.81 \\
\hline Cough & $\begin{array}{l}67 \\
(98.5)\end{array}$ & $85(94.4)$ & $86(91.5)$ & $\begin{array}{l}49 \\
(100.0)\end{array}$ & $\begin{array}{l}47 \\
(97.9)\end{array}$ & $19(100.0)$ & $\begin{array}{l}18 \\
(94.7)\end{array}$ & $\begin{array}{l}38 \\
(90.5)\end{array}$ & $67(89.3)$ & 0.16 \\
\hline Fever & $\begin{array}{l}36 \\
(52.9)\end{array}$ & $50(55.6)$ & $53(56.4)$ & $\begin{array}{l}30 \\
(61.2)\end{array}$ & $\begin{array}{l}29 \\
(60.4)\end{array}$ & $17(89.5)$ & $\begin{array}{l}6 \\
(31.6)\end{array}$ & $21(50)$ & $36(48)$ & 0.91 \\
\hline Malaise & $\begin{array}{l}52 \\
(76.5)\end{array}$ & $66(73.3)$ & $70(74.5)$ & $\begin{array}{l}37 \\
(75.5)\end{array}$ & $\begin{array}{l}32 \\
(66.7)\end{array}$ & $14(73.7)$ & $\begin{array}{l}15 \\
(78.9)\end{array}$ & $34(81)$ & $56(74.7)$ & 0.90 \\
\hline Loss of weight & $\begin{array}{l}58 \\
(85.3)\end{array}$ & $72(80.0)$ & $67(71.3)$ & $\begin{array}{l}43 \\
(87.8)\end{array}$ & $\begin{array}{l}37 \\
(77.1)\end{array}$ & $18(94.7)$ & $\begin{array}{l}15 \\
(78.9)\end{array}$ & $\begin{array}{l}35 \\
(83.3)\end{array}$ & $49(65.3)$ & 0.90 \\
\hline Night sweats & $\begin{array}{l}48 \\
(70.6)\end{array}$ & $55(61.1)$ & $54(57.4)$ & $\begin{array}{l}36 \\
(73.5)\end{array}$ & $\begin{array}{l}32 \\
(66.7)\end{array}$ & $11(57.9)$ & $\begin{array}{l}12 \\
(63.2)\end{array}$ & $\begin{array}{l}23 \\
(54.8)\end{array}$ & $43(57.3)$ & 0.23 \\
\hline Hemoptysis & $\begin{array}{l}21 \\
(30.9)\end{array}$ & $20(22.2)$ & $40(42.6)$ & $\begin{array}{l}12 \\
(24.5)\end{array}$ & $6(12.5)$ & $6(31.6)$ & $\begin{array}{l}9 \\
(47.4)\end{array}$ & $\begin{array}{l}14 \\
(33.3)\end{array}$ & $34(45.3)$ & $<0.01$ \\
\hline $\begin{array}{l}\text { Lack of } \\
\text { appetite }\end{array}$ & $\begin{array}{l}51 \\
(75.0)\end{array}$ & $61(67.8)$ & $57(60.6)$ & $\begin{array}{l}39 \\
(79.6)\end{array}$ & $\begin{array}{l}32 \\
(66.7)\end{array}$ & $16(84.2)$ & $\begin{array}{l}12 \\
(63.2)\end{array}$ & $\begin{array}{l}29 \\
(69.0)\end{array}$ & $41(54.7)$ & 0.16 \\
\hline Dyspnea & $\begin{array}{l}39 \\
(57.4)\end{array}$ & $54(60)$ & $65(69.1)$ & $\begin{array}{l}27 \\
(55.1)\end{array}$ & $\begin{array}{l}29 \\
(60.4)\end{array}$ & $14(73.7)$ & $\begin{array}{l}12 \\
(63.2)\end{array}$ & $\begin{array}{l}25 \\
(59.5)\end{array}$ & $51(68.0)$ & 0.25 \\
\hline Comorbidities & $\begin{array}{l}9 \\
(13.2)\end{array}$ & $17(18.8)$ & $31(32.9)$ & $4(8.9)$ & $12(25)$ & $1(5.3)$ & $\begin{array}{l}5 \\
(26.3)\end{array}$ & $\begin{array}{l}5 \\
(11.9)\end{array}$ & $6(8)$ & 0.85 \\
\hline $\begin{array}{l}\text { Smoking } \\
\text { History }\end{array}$ & $\begin{array}{l}28 \\
(41.2)\end{array}$ & $28(31.5)$ & $19(20.2)$ & $24(49)$ & $\begin{array}{l}18 \\
(37.5)\end{array}$ & $4(21.1)$ & $\begin{array}{l}4 \\
(21.1)\end{array}$ & $\begin{array}{l}10 \\
(24.4)\end{array}$ & $15(20)$ & 0.15 \\
\hline Illicit drug use & $3(4.4)$ & $8(9)$ & $14(14.9)$ & $2(4.1)$ & $1(2.1)$ & $1(5.3)$ & $1(5.3)$ & $\begin{array}{l}7 \\
(17.1)\end{array}$ & $13(17.3)$ & 0.83 \\
\hline $\begin{array}{l}\text { Alcohol } \\
\text { consumption }\end{array}$ & $\begin{array}{l}11 \\
(16.2)\end{array}$ & $32(36)$ & $38(40.4)$ & $\begin{array}{l}7 \\
(14.3)\end{array}$ & $3(6.3)$ & $1(5.3)$ & $\begin{array}{l}4 \\
(21.1)\end{array}$ & $\begin{array}{l}29 \\
(70.7)\end{array}$ & 37 (49.3) & $<0.01$ \\
\hline Metformin use & $\begin{array}{l}17 \\
(42.5)\end{array}$ & $0(0)$ & $0(0)$ & $\begin{array}{l}10 \\
(47.6)\end{array}$ & $0(0)$ & $0(0)$ & $\begin{array}{l}7 \\
(36.8)\end{array}$ & $0(0)$ & $0(0)$ & $<0.01$ \\
\hline FPG (mg/dL) & $\begin{array}{l}148.2 \\
{[102.2-} \\
286.8]\end{array}$ & $\begin{array}{l}93.15[82.6 \\
-100.8]\end{array}$ & 89 [84.0-93.7] & $\begin{array}{l}122 \\
{[95-} \\
231]\end{array}$ & $\begin{array}{l}85[79- \\
92]\end{array}$ & 81 [78.0-89.0] & $\begin{array}{l}254.1 \\
{[150.4-} \\
311.6]\end{array}$ & $\begin{array}{l}100.7 \\
{[95.7-} \\
104.2]\end{array}$ & 89.9 [85.7-94.7] & $<0.01$ \\
\hline HbA1c (\%) & $\begin{array}{l}8.1 \\
{[6.8-} \\
12.9]\end{array}$ & $\begin{array}{l}5.7[5.3- \\
6.1]\end{array}$ & $5.1[4.7-5.3]$ & $\begin{array}{l}7.6 \\
{[6.7-} \\
11.9]\end{array}$ & $\begin{array}{l}6[5.7- \\
6.2]\end{array}$ & $5.5[4.8-5.6]$ & $\begin{array}{l}10.8 \\
{[7.4-} \\
13.5]\end{array}$ & $\begin{array}{l}5.1 \\
{[5.0-} \\
5.6]\end{array}$ & $5[4.7-5.2]$ & $<0.01$ \\
\hline OGTT (mg/dL) & $\begin{array}{l}141 \\
{[111-} \\
189]\end{array}$ & $\begin{array}{l}127.1 \\
{[105.8-} \\
156.3]\end{array}$ & $\begin{array}{l}101.6[83.3- \\
117.7]\end{array}$ & $\begin{array}{l}152 \\
{[109.0-} \\
196.5]\end{array}$ & $\begin{array}{l}121 \\
{[100.0-} \\
153.0]\end{array}$ & $\begin{array}{l}92.5[75.0- \\
109.0]\end{array}$ & $\begin{array}{l}119.5 \\
\text { [119.5- } \\
119.5]\end{array}$ & $\begin{array}{l}132.7 \\
{[108.5-} \\
157.4]\end{array}$ & $\begin{array}{l}105.2[85.8- \\
121.4]\end{array}$ & $<0.01$ \\
\hline Prior TB & $\begin{array}{l}17 \\
(25)\end{array}$ & $15(16.7)$ & $14(14.9)$ & $\begin{array}{l}12 \\
(24.5)\end{array}$ & $\begin{array}{l}7 \\
(14.6)\end{array}$ & $4(21.1)$ & $\begin{array}{l}5 \\
(26.3)\end{array}$ & $\begin{array}{l}8 \\
(19.0)\end{array}$ & $10(13.3)$ & 0.23 \\
\hline $\begin{array}{l}\text { BCG } \\
\text { vaccination }\end{array}$ & $\begin{array}{l}50 \\
(73.5)\end{array}$ & $76(85.4)$ & $86(91.5)$ & $\begin{array}{l}33 \\
(67.3)\end{array}$ & $\begin{array}{l}38 \\
(79.2)\end{array}$ & $15(78.9)$ & $\begin{array}{l}17 \\
(89.5)\end{array}$ & $\begin{array}{l}38 \\
(92.7)\end{array}$ & $71(94.7)$ & $<0.01$ \\
\hline TB contact & $\begin{array}{l}16 \\
(23.5)\end{array}$ & $24(26.7)$ & $43(45.7)$ & $\begin{array}{l}13 \\
(26.5)\end{array}$ & $\begin{array}{l}15 \\
(31.3)\end{array}$ & $3(15.8)$ & $\begin{array}{l}3 \\
(15.8)\end{array}$ & $\begin{array}{l}9 \\
(21.4)\end{array}$ & $40(53.3)$ & $<0.01$ \\
\hline
\end{tabular}




\begin{tabular}{|c|c|c|c|c|c|c|c|c|c|}
\hline \multicolumn{4}{|l|}{ AFB smear } & \multirow[b]{2}{*}{$\begin{array}{l}17 \\
(34.7)\end{array}$} & \multirow[b]{2}{*}{$\begin{array}{l}25 \\
(52.1)\end{array}$} & \multirow[b]{2}{*}{$8(42.1)$} & \multirow[b]{2}{*}{$\begin{array}{l}5 \\
(26.3)\end{array}$} & \multicolumn{2}{|r|}{0.28} \\
\hline Negative & $\begin{array}{l}22 \\
(32.4)\end{array}$ & $40(44.4)$ & $48(51.6)$ & & & & & $\begin{array}{l}15 \\
(35.7)\end{array}$ & $40(54.1)$ \\
\hline Scanty & $1(1.5)$ & $2(2.2)$ & $2(2.2)$ & $0(0)$ & $0(0)$ & $0(0)$ & $1(5.3)$ & $2(4.8)$ & $2(2.7)$ \\
\hline $1+$ & $\begin{array}{l}20 \\
(29.4)\end{array}$ & $16(17.8)$ & 18 (19.4) & $\begin{array}{l}17 \\
(34.7)\end{array}$ & $\begin{array}{l}7 \\
(14.6)\end{array}$ & $3(15.8)$ & $\begin{array}{l}3 \\
(15.8)\end{array}$ & $\begin{array}{l}9 \\
(21.4)\end{array}$ & $15(20.3)$ \\
\hline $2+$ & $\begin{array}{l}12 \\
(17.6)\end{array}$ & $10(11.1)$ & $11(11.8)$ & $\begin{array}{l}9 \\
(18.4)\end{array}$ & $4(8.3)$ & $5(26.3)$ & $\begin{array}{l}3 \\
(15.8)\end{array}$ & $\begin{array}{l}6 \\
(14.3)\end{array}$ & $6(8.1)$ \\
\hline $3+$ & $\begin{array}{l}13 \\
(19.1)\end{array}$ & $22(24.4)$ & $14(15.1)$ & $\begin{array}{l}6 \\
(12.2)\end{array}$ & $\begin{array}{l}12 \\
(25.0)\end{array}$ & 3 (15.8) & $\begin{array}{l}7 \\
(36.8)\end{array}$ & $\begin{array}{l}10 \\
(23.8)\end{array}$ & $11(14.9)$ \\
\hline L-J culture & & & & & & & & & $<0.01$ \\
\hline Negative & $6(8.8)$ & $11(12.5)$ & $25(27.5)$ & $2(4.1)$ & $2(4.2)$ & $0(0)$ & $\begin{array}{l}4 \\
(21.1)\end{array}$ & $\begin{array}{l}9 \\
(22.5)\end{array}$ & 25 (34.7) \\
\hline Scanty & $2(2.9)$ & $6(6.8)$ & $8(8.8)$ & $1(2)$ & $1(2.1)$ & $0(0)$ & $1(5.3)$ & $5(12.5)$ & 8 (11.1) \\
\hline $1+$ & $\begin{array}{l}31 \\
(45.6)\end{array}$ & 39 (44.3) & $41(45.1)$ & $\begin{array}{l}19 \\
(38.8)\end{array}$ & $\begin{array}{l}21 \\
(43.8)\end{array}$ & $8(42.1)$ & $\begin{array}{l}12 \\
(63.2)\end{array}$ & $18(45)$ & $33(45.8)$ \\
\hline $2+$ & $\begin{array}{l}22 \\
(32.4)\end{array}$ & $13(14.8)$ & $7(7.7)$ & $\begin{array}{l}20 \\
(40.8)\end{array}$ & $\begin{array}{l}9 \\
(18.8)\end{array}$ & $4(21.1)$ & $\begin{array}{l}2 \\
(10.5)\end{array}$ & $4(10)$ & $3(4.2)$ \\
\hline $3+$ & $4(5.9)$ & 17 (19.3) & $7(7.7)$ & $4(8.2)$ & $\begin{array}{l}13 \\
(27.1)\end{array}$ & $4(21.1)$ & $0(0)$ & $4(10)$ & $3(4.2)$ \\
\hline \multicolumn{10}{|c|}{$\begin{array}{l}\text { Data are represented as median with interquartile range [25th - 75th percentile] or frequency (percentage). Comparison of TB patients between Brazil } \\
\text { and Peru and glycemic groups was performed using Kruskal-Wallis Test for quantitative variables and the Mantel-Haenszel Test for categorical } \\
\text { variables. P < } 0.05 \text { was considered statistically significant. Comorbidities: Renal disease and/or Asthma and/or Hypertension; Smoking history: Past } \\
\text { or current cigarette smoker; Illicit Drugs Use: Past or current illicit drug use (marijuana, cocaine, heroin or crack); Chronic Alcoholism: Past or current } \\
\text { any consumption of alcohol; Metformin use: Metformin use in patients with dysglycemia; Prior TB: previous diagnosis of active tuberculosis; DM: } \\
\text { Diabetes; PDM: Prediabetes; FPG Fasting Plasma Glucose; HbA1c Glycated Hemoglobin; OGTT Oral Glucose Tolerance Test; BMl: Body Mass Index; } \\
\text { BCG: Bacillus Calmette-Guérin; AFB Acid-Fast Bacilli; L-J Löwenstein-Jensen. }\end{array}$} \\
\hline
\end{tabular}

\section{Figures}




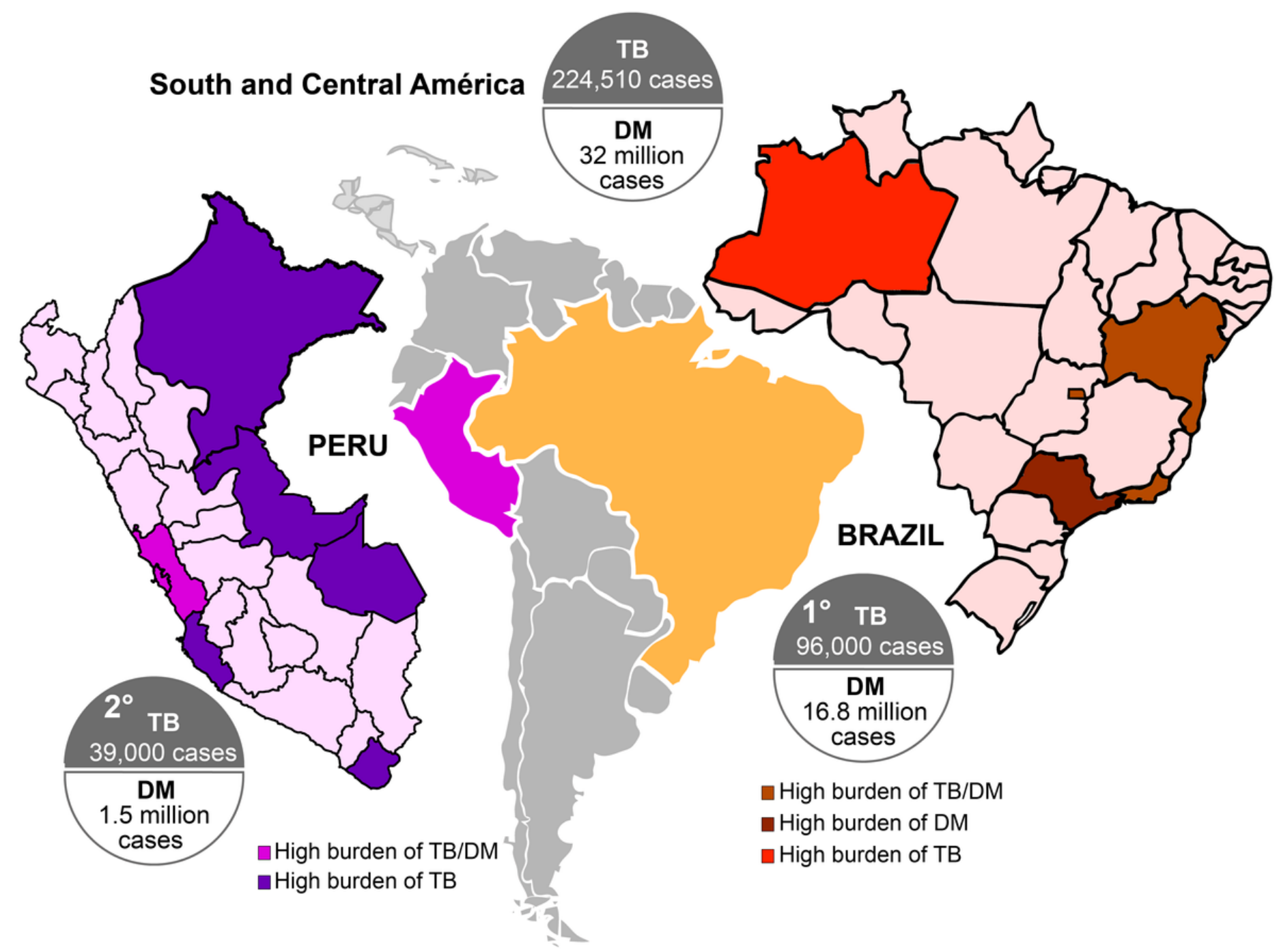

Figure 1

Epidemiological distribution of TB and DM cases across Brazil and Peru. The figure shows the distribution of TB and DM burden by Country. Inside the Countries, in the Map, it is displayed the distribution of TB and DM overload by state/province. 

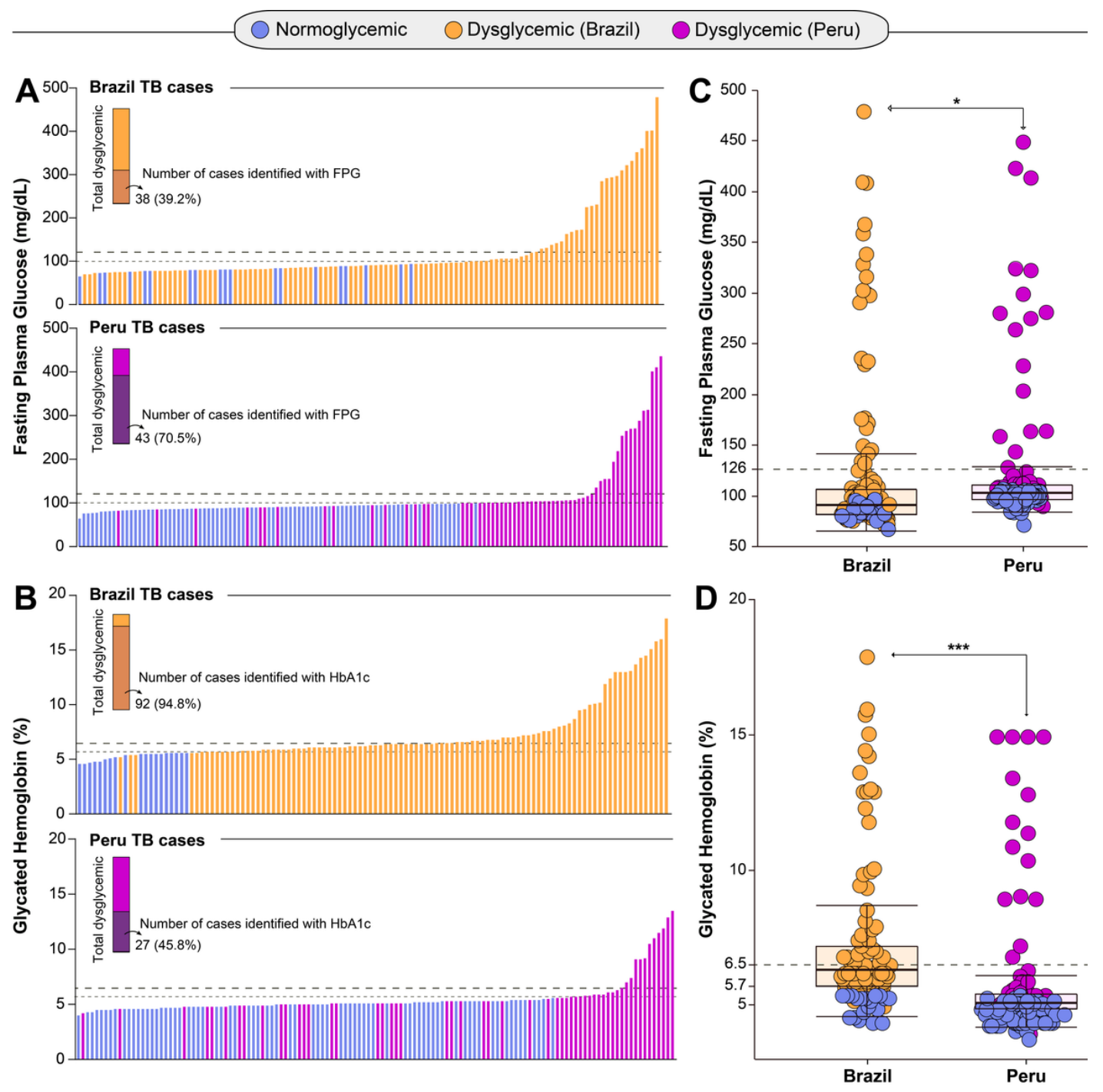

Figure 2

Differences in distribution of Fasting Plasma Glucose and Glycated Hemoglobin levels in TB patients stratified by country. (A) Distribution of FPG levels of TB patients in Brazilian and Peruvian populations are shown. (B) Distribution of values obtained in HbA1c test in TB cases in Brazil and Peru are exhibited. The patients are colored according to the glycemic status. Reference intervals marking dysglycemia are displayed by transversal lines, where lower limit representing its reference for prediabetes, and upper limit representing its reference for diabetes. Box plots depicting the distribution of the FPG values (C) as well as levels of HbA1c (D) in the subgroups of Brazilian and Peruvian populations amongst TB patients are shown. The differences in median values (and IQR) of FPG and HbA1c between groups were compared using the Mann-Whitney $U$ test. $\left({ }^{\star} p<0.05,{ }^{\star * \star} p<0.001\right)$. Dysglycemic: prediabetes and diabetes; FPG: Fasting Plasma Glucose; HbA1c: Glycated Hemoglobin. 
A
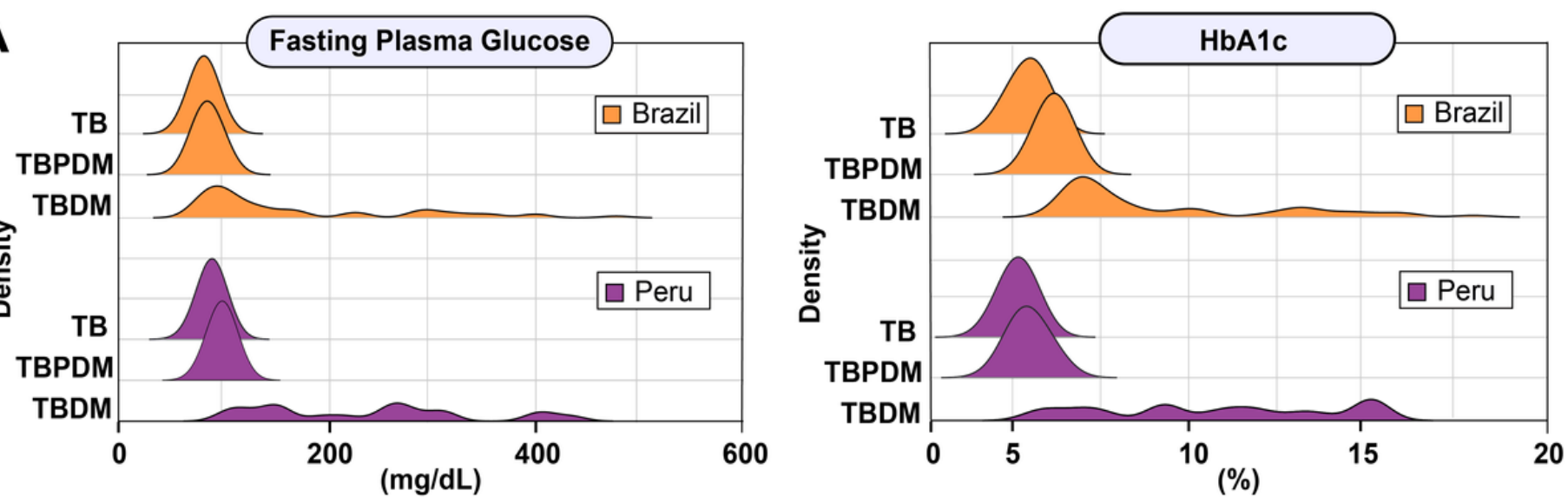

B

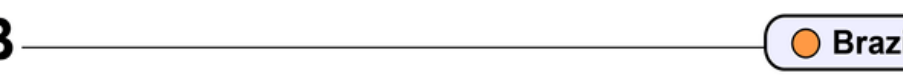

\section{OPeru}
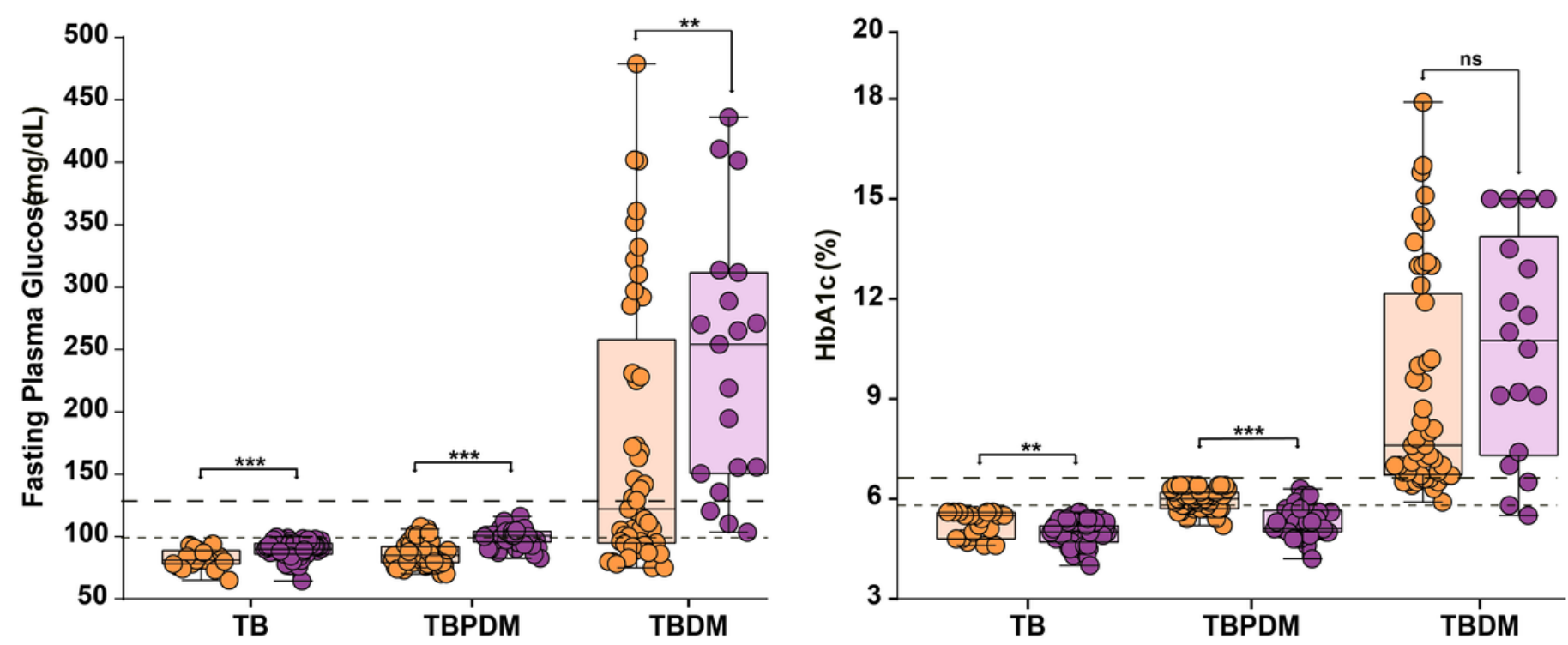

Figure 3

Dissimilarities over distribution of glycemic markers in TB patients stratified by glycemic status in Brazil and Peru. (A) Data show distribution of Fasting Plasma Glucose and Glycated Hemoglobin levels obtained in TB patients from both countries. TB patients were stratified according to glycemic status, in normoglycemic, Prediabetes and Diabetes Mellitus. (B) Box plot of glycemic markers represent distribution of the values obtained in Hb1 Ac (left panel) and FPG (right panel) tests of TB patients stratified based on their DM status. Reference intervals marking dysglycemia are displayed by transversal lines, where lower limit points its reference for prediabetes, and upper limit its reference for diabetes. Box plots represent the distribution of the tests results between study groups (with medians, interquartile ranges, and top and lowest values). Differences between groups were tested using the Mann-Whitney U test $\left({ }^{\star} \mathrm{p}<0.05 .{ }^{* \star} \mathrm{p}<0.01 .{ }^{* \star *} \mathrm{p}<0.001\right)$. TB: Tuberculosis; TB-PDM: Tuberculosis and Prediabetes and TBDM: Tuberculosis and Diabetes Mellitus; non-DM/PDM: normoglycemic; PDM: prediabetes; DM: Diabetes Mellitus; FPG: Fasting Plasma Glucose (mg/dL; Y axis scale follows a geometric progression of ratio 2); HbA1c: glycated hemoglobin (\%). 
A

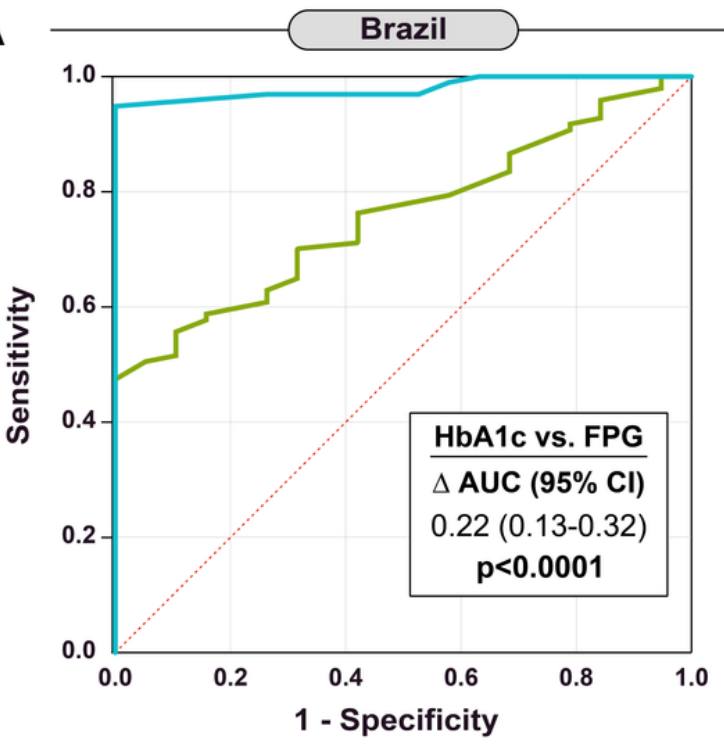

\begin{tabular}{lccccc}
\hline Test & $\begin{array}{c}\text { AUC } \\
(95 \% \mathrm{Cl})\end{array}$ & p-value & $\begin{array}{c}\text { cut-off } \\
\text { value }\end{array}$ & $\begin{array}{c}\text { Sensitivity } \\
(\mathbf{9 5 \%} \mathrm{Cl})\end{array}$ & $\begin{array}{c}\text { Specificity } \\
(95 \% \mathrm{Cl})\end{array}$ \\
\hline - FPG & 0.76 & $<0.0001$ & $>91.0$ & 55.7 & 89.5 \\
& $(0.67-0.83)$ & & & $(45.2-65.8)$ & $(66.9-98.7)$ \\
- HbA1c & 0.98 & & 94.9 & 100 \\
& $(0.93-1.00)$ & $<0.0001$ & $>5.6$ & $(88.4-98.3)$ & $(82.4-100)$ \\
\hline
\end{tabular}

C

\begin{tabular}{lcc}
\hline $\begin{array}{l}\text { Difference of AUCs values } \\
\text { between Brazil and Peru }\end{array}$ & $\begin{array}{c}\Delta \text { AUC } \\
(\mathbf{9 5 \%} \mathrm{Cl})\end{array}$ & p-value \\
\hline $\begin{array}{l}\text { Difference between } \\
\text { areas (FPG): }\end{array}$ & $\begin{array}{c}0.15 \\
(0.04-0.26)\end{array}$ & 0.0089 \\
$\begin{array}{l}\text { Difference between } \\
\text { areas (HbA1c): }\end{array}$ & $\begin{array}{c}0.19 \\
(0.11-0.28)\end{array}$ & $<0.0001$ \\
\hline
\end{tabular}

B
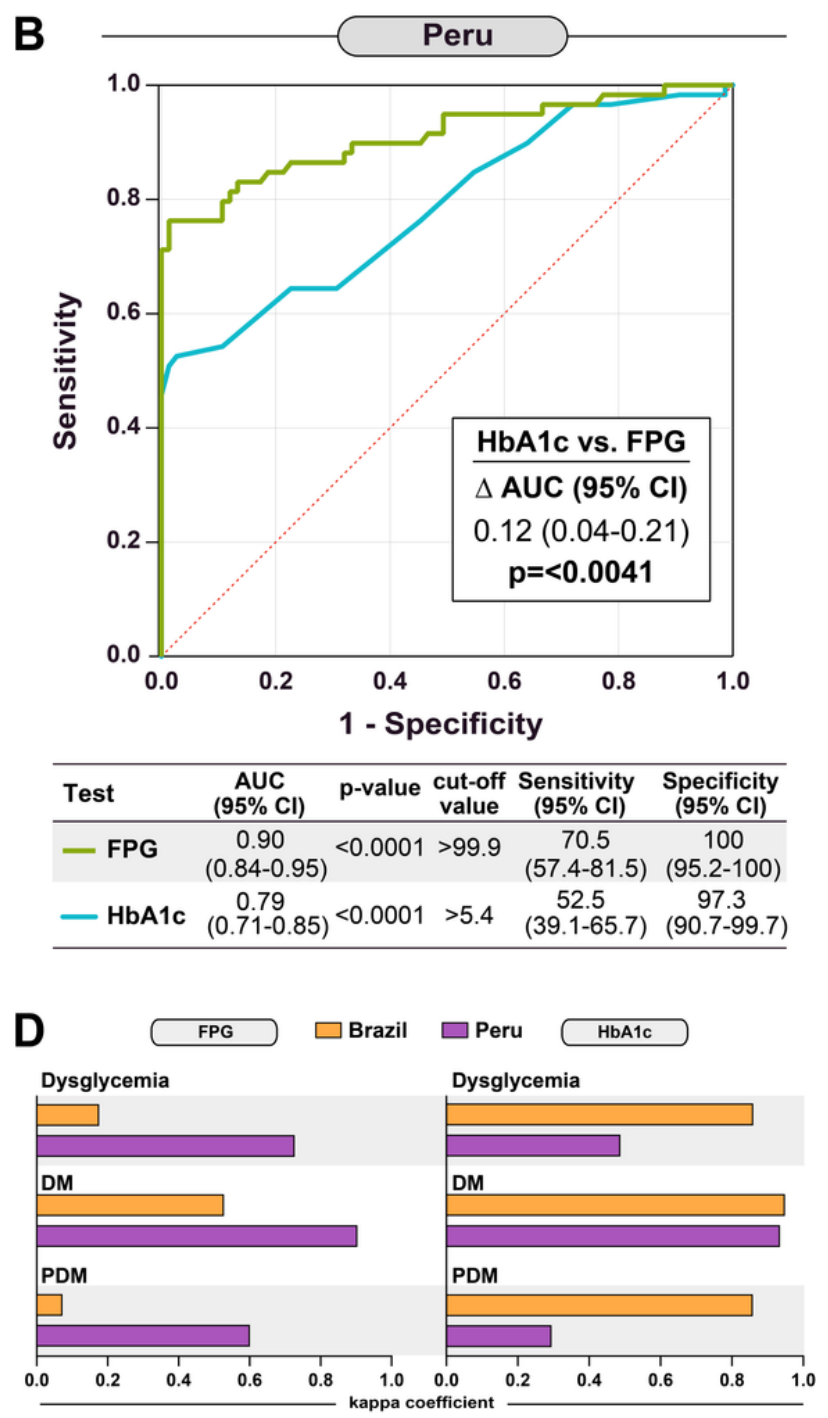

Figure 4

Accuracy disagreement on diagnose of glycemic disorders by FPG and HbA1c markers stratified by country. Receiver Operator Characteristics (ROC) curve analysis was employed to determine the accuracy of glycemic markers to predict dysglycemia in TB patients, using fasting glucose levels (FPG) and glycated hemoglobin ( $\mathrm{Hb} 1 \mathrm{Ac}$ ), in Brazil (A) and Peru (B). Differences of area under the ROC curve (AUC) values were also assessed, with p-values and $z$ statistic results referring to comparisons within Brazilian (A) and Peruvian (B) cohorts and between countries (C). (D) Kappa statistics was performed to analyze agreement of glycemic markers for diagnosis of dysglycemia, DM and PDM. Data represent the kappa coefficient in each country. Dysglycemic: prediabetes and diabetes; DM: diabetes mellitus; PDM: prediabetes; FPG: fasting Plasma Glucose; HbA1c: glycated Hemoglobin.

\section{Supplementary Files}

This is a list of supplementary files associated with this preprint. Click to download.

- SupplementaryFigure.pdf 